\title{
Rab6A as a Pan-Astrocytic Marker in Mouse and Human Brain, and Comparison with Other Glial Markers (GFAP, GS, Aldh1L1, SOX9)
}

\author{
Linda Melzer ${ }^{1}$, Thomas M. Freiman ${ }^{2}$ and Amin Derouiche ${ }^{1, *(D)}$ \\ 1 Institute of Anatomy II, Goethe-University, D-60590 Frankfurt am Main, Germany; Linda.Spiess93@gmx.de \\ 2 Department of Neurosurgery, Rostock University Medical Center, D-18055 Rostock, Germany; \\ Thomas.Freiman@med.uni-rostock.de \\ * Correspondence: Derouiche@em.uni-frankfurt.de; Tel.: +49-69-6301-6019
}

Citation: Melzer, L.; Freiman, T.M.; Derouiche, A. Rab6A as a Pan-Astrocytic Marker in Mouse and Human Brain, and Comparison with Other Glial Markers (GFAP, GS, Aldh1L1, SOX9). Cells 2021, 10, 72. https: / / doi.org/10.3390/ cells10010072

Received: 12 August 2020 Accepted: 30 December 2020 Published: 5 January 2021

Publisher's Note: MDPI stays neutral with regard to jurisdictional clai$\mathrm{ms}$ in published maps and institutional affiliations.

Copyright: (C) 2021 by the authors. Licensee MDPI, Basel, Switzerland. This article is an open access article distributed under the terms and conditions of the Creative Commons Attribution (CC BY) license (https:// creativecommons.org/licenses/by/ $4.0 /)$.

\begin{abstract}
Astrocytes contribute to many higher brain functions. A key mechanism in glia-to-neuron signalling is vesicular exocytosis; however, the identity of exocytosis organelles remains a matter of debate. Since vesicles derived from the trans-Golgi network (TGN) are not considered in this context, we studied the astrocyte TGN by immunocytochemistry applying anti-Rab6A. In mouse brain, Rab6A immunostaining is found to be unexpectedly massive, diffuse in all regions, and is detected preferentially and abundantly in the peripheral astrocyte processes, which is hardly evident without glial fibrillary acid protein (GFAP) co-staining. All cells positive for the astrocytic markers glutamine synthetase (GS), GFAP, aldehyde dehydrogenase 1 family member L1 (Aldh1L1), or SRY (sex determining region Y)-box 9 (SOX9) were Rab6A ${ }^{+}$. Rab6A is excluded from microglia, oligodendrocytes, and NG2 cells using cell type-specific markers. In human cortex, Rab6A labelling is very similar and associated with $\mathrm{GFAP}^{+}$astrocytes. The mouse data also confirm the specific astrocytic labelling by Aldh1L1 or SOX9; the astrocyte-specific labelling by GS sometimes debated is replicated again. In mouse and human brain, individual astrocytes display high variability in Rab6 $\mathrm{A}^{+}$structures, suggesting dynamic regulation of the glial TGN. In summary, Rab6A expression is an additional, global descriptor of astrocyte identity. Rab6A might constitute an organelle system with a potential role of Rab6A in neuropathological and physiological processes.
\end{abstract}

Keywords: trans-Golgi network; astrocyte heterogeneity; immunocytochemistry

\section{Introduction}

Astrocytes, in addition to their metabolic and homeostatic functions, specifically contribute to neuronal network operation and physiological functions in naturally occurring behaviors [1-8]. A key mechanism in signalling from the glial to the neuronal domain is vesicular exocytosis, mostly involving small molecule "gliotransmitters" such as glutamate and D-serine [9]. Moreover, astrocyte-derived proteins, such as S100 $\beta$, are released to the extracellular space to modulate neuronal firing [10]. Although exocytotic organelles have in fact been observed in astrocytes in situ [11-14], their identity has remained a matter of debate [15-19]. In particular, there is no general idea as to what extent astrocytic exocytosis organelles occur in brain, or what their biogenesis is. Vesicles derived from the trans-Golgi network (TGN) have not been considered in this context. Moreover, there are very few if any published data on the TGN in astrocytes. We studied the possible presence and distribution of TGN in astrocytes in situ by immunocytochemistry using the TGN marker Rab6A. Although widely studied in cell biology [20], Rab6 is relatively unknown in the field of neuroscience.

Rab6 belongs to the superfamiliy of Ras-GTPases and has its main subtypes A and B [21] with two genes localized on separate chromosomes [22]. Rab6 proteins are involved in the regulation of intracellular membrane traffic [20]. Members of the Rab6 family of 
proteins localize to the TGN, the Golgi cisterns, and the tubulovesicular organelles moving along the plus end of microtubuli [23]. Rab6 plays a role in retrograde endosome to Golgi transport, it also mediates the Golgi to ER vesicle trafficking [20,24]. Rab6B is regarded as the neuronal Rab6 subtype within the CNS [20,25], but there is no information as to the presence or localization of Rab6A in the CNS.

We thus studied the possible presence of Rab6A in mouse and human brain. We find it in all cells labelled by the astrocytic markers glutamine synthetase (GS), glial fibrillary acid protein (GFAP), aldehyde dehydrogenase 1 family member L1 (Aldh1L1), and SRY (sex determining region Y)-box 9 (SOX9), and it is excluded from other glial cell types.

\section{Materials and Methods}

\subsection{Tissues}

The mouse data reported are based on the brains from 5 adult (10-12 weeks) C57BL/6 mice. Animal handling and sacrifice were according to German government law. Animals were killed by an overdose of isofluorane and perfused through the ascending aorta with a brief rinse $(0.9 \%$ saline) followed by fixative ( $4 \%$ paraformaldehyde in $0.1 \mathrm{M}$ phosphate buffer (PB; $\mathrm{pH} 7.3)$ ) for $15 \mathrm{~min}$. The brains were taken out and immersion-fixed in the same fixative to complete an overall fixation time of $2 \mathrm{~h}$ and rinsed several times in PB. Cryostat sections $(12-14 \mu \mathrm{m})$, prepared from the brains of 2 mice, were used for NG2 labelling. All other labellings were carried out on $100 \mu \mathrm{m}$ vibratome sections.

Human tissue from temporal or frontal cortex was obtained from 3 patients during epilepsy surgery (Table 1). The specimens studied here were from surgical access path, or from peripheral portion of resection, and considered largely non-affected by disease. Written consent was obtained from all patients, and the study was approved by the local ethics committee (Medical Faculty, Goethe-Universität Frankfurt am Main, code no. 4/09; project no. SNO-09-2014). The tissue was placed in fixative solution (as above) immediately after resection, cut into $4 \mathrm{~mm}$ slabs, and fixed for a total of $16 \mathrm{~h}$. Neuropathological diagnosis was performed by the Department of Neuropathology, Goethe University, University Hospital, Frankfurt am Main, Germany.

Table 1. Patient cases.

\begin{tabular}{|c|c|c|c|c|}
\hline Patient Case & Age (y) & Sex & Neuropathological Diagnosis & Tissue Studied \\
\hline I & 31 & $\mathrm{~m}$ & $\begin{array}{l}\text { focal cortical dysplasia (Palmini II, ILAE IIa) temporal cortex } \\
\text { and amygdala, hippocampal sclerosis (ILAE III) }\end{array}$ & temporal cortex \\
\hline II & 15 & $\mathrm{~m}$ & focal cortical dysplasia (ILAE IIb), frontal cortex & frontal cortex \\
\hline III & 20 & $\mathrm{~m}$ & $\begin{array}{l}\text { ganglioglioma WHO grade I with hippocampal infiltration } \\
\text { (grade of sclerosis not rated) }\end{array}$ & cortex from access path \\
\hline
\end{tabular}

\subsection{Immunocytochemistry}

All solutions were prepared in PB. Animal tissues were first incubated for $30 \mathrm{~min}$ with $1 \% \mathrm{NaBH}_{4}$ at room temperature, rinsed for at least $1 \mathrm{~h}$, and then rinsed with mouse Ig-blocking reagent ( $3 \%$, M.O.M.) for $1 \mathrm{~h}$. After another brief rinse, sections were treated for $30 \mathrm{~min}$ with normal horse serum $(10 \%)$. Incubation with primary antibodies was in $1 \%$ normal horse serum, overnight, and at $4{ }^{\circ} \mathrm{C}$ (for antibodies and concentrations, see Table 2A). Twenty minutes of rinsing preceded reaction with secondary antibody solution (for secondary antibodies and concentrations, see Table 2B). In case of a biotinylated secondary antibody, sections were then rinsed for another $20 \mathrm{~min}$ and incubated for $1 \mathrm{~h}$ with fluorochrome-conjugated streptavidin. Nuclear staining was performed with bisbenzimidine. The sections were rinsed for $10 \mathrm{~min}$ and coverslipped in fluo-escence mounting medium (Aqua Poly Mount, Polysciences Inc., Warrington, PA, USA). 
Table 2. Primary antibodies.

\begin{tabular}{|c|c|c|c|}
\hline \multicolumn{4}{|c|}{ A } \\
\hline Antibody & Host & Supplier, Cat\#, RRID ${ }^{1}$ & Concentration \\
\hline Aldh1L1 & rabbit & $\begin{array}{l}\text { Sigma-Aldrich, HPA036900, } \\
\text { RRID:AB_10672273 }\end{array}$ & $1: 200$ \\
\hline CNPase & rabbit & $\begin{array}{l}\text { Synaptic Systems, } 355 \text { 002, } \\
\text { RRID:AB_2620111 }\end{array}$ & $1: 500$ \\
\hline GFAP & chicken & Millipore, AB5541, RRID:AB_177521 & $1: 500$ \\
\hline GFAP Al488 & mouse & $\begin{array}{l}\text { Cell Signaling Technology, 3655, } \\
\text { RRID:AB_2263284 }\end{array}$ & $1: 100$ \\
\hline GS & goat & $\begin{array}{l}\text { Santa Cruz Biotechnology, sc-6640, } \\
\text { RRID:AB_641095 }\end{array}$ & $1: 500$ \\
\hline Iba1 & goat & Abcam, ab5076, RRID:AB_2224402 & 1:1000 \\
\hline NeuN & guinea pig & $\begin{array}{l}\text { Synaptic Systems, 266004, } \\
\text { RRID:AB_2619988 }\end{array}$ & 1:2000 \\
\hline NG2 & rabbit & Millipore, AB5320, RRID:AB_91789 & $1: 500$ \\
\hline $\operatorname{Rab6A}^{2}$ & mouse & $\begin{array}{l}\text { Sigma-Aldrich, WH0005870M1, } \\
\text { RRID:AB_1843236 }\end{array}$ & $1: 5000$ \\
\hline Sox9 & goat & $\begin{array}{l}\text { R and D Systems, AF3075, } \\
\text { RRID:AB_2194160 }\end{array}$ & $1: 500$ \\
\hline \multicolumn{4}{|c|}{ B } \\
\hline Antibody/Re & & Supplier & Concentration \\
\hline Donkey-anti- & n-AMCA & Jackson Immunoresearch & $1: 100$ \\
\hline Donkey-anti- & Alexa 488 & Jackson Immunoresearch & $1: 100$ \\
\hline Donkey-anti- & -Alexa 488 & Jackson Immunoresearch & $1: 100$ \\
\hline Donkey-anti- & -Alexa 647 & Jackson Immunoresearch & $1: 100$ \\
\hline Donkey-anti- & -Сy3 & Jackson Immunoresearch & 1:1000 \\
\hline Donkey-anti- & $y 488$ & Jackson Immunoresearch & $1: 100$ \\
\hline Donkey-anti- & pig Alexa 488 & Jackson Immunoresearch & $1: 100$ \\
\hline Horse-anti-ra & otin & Vector Laboratories & $1: 217$ \\
\hline Horse-anti-m & iotin & Vector Laboratories & $1: 217$ \\
\hline Horse-anti-g & & Vector Laboratories & $1: 217$ \\
\hline Bisbenzimidi & & Sigma & 1:2000 \\
\hline Mouse-Ig-Blc & Reagent (M.O.M.) & Vector Laboratories & $3 \%$ \\
\hline Normal hors & & Vector Laboratories & $1 \%, 10 \%$ \\
\hline Streptavidin- & & Vector Laboratories & 1:100 \\
\hline Streptavidin- & & Vector Laboratories & 1:1000 \\
\hline
\end{tabular}

${ }_{1}^{1}$ Antibody reference according to the Resource Identification Initiative at https://scicrunch.org/resources

${ }^{2}$ Antibody activity fades after several months at $-80^{\circ} \mathrm{C}$.

$100 \mu \mathrm{m}$ thick vibratome sections were prepared from the human cortex tissue slabs and immunoreacted for Rab6A and GFAP, as above, unless otherwise stated. In detail, this included sequential incubations in normal horse serum, anti-Rab6A (overnight, $4{ }^{\circ} \mathrm{C}$ ), donkey-anti-mouse-Cy3, anti-GFAP Al488 (overnight, $4{ }^{\circ} \mathrm{C}$ ), and coverslipping.

Sections untreated except for $\mathrm{NaBH}_{4}$ were used as controls to assess autofluorescence. To control for specificity of the detection system in Rab6A single staining, sections were immunoreacted without the primary antibody. For a given multiple staining, the series of controls consisted of stainings each omitting only 1 of the 2 or 3 primary antibodies, thus 
controlling for fluorescence filter bleedthrough, background, and antibody crossreactivities. The results reported were obtained at least in 3 independent staining runs. An overview of the staining combinations carried out in mouse and human tissue is given in Table 3 .

Table 3. Staining combinations.

\begin{tabular}{|c|c|c|c|}
\hline Double and Triple Stainings & & & Species \\
\hline \multicolumn{4}{|l|}{ Astrocyte selectivity } \\
\hline GFAP & \multirow{2}{*}{\multicolumn{2}{|c|}{ Rab6A }} & \multirow{2}{*}{ mouse } \\
\hline SOX9 & & & \\
\hline GFAP & Rab6A & & human \\
\hline \multicolumn{4}{|l|}{ Astrocyte specificity } \\
\hline \multicolumn{4}{|l|}{ Iba1 } \\
\hline CNPase & \multirow[t]{2}{*}{ Rab6A } & & \multirow[t]{2}{*}{ mouse } \\
\hline \multicolumn{2}{|l|}{ NG2 } & & \\
\hline \multicolumn{4}{|l|}{ Pan-astrocyte selectivity } \\
\hline \multirow{2}{*}{ GFAP } & \multirow{2}{*}{ Rab6A } & GS & \multirow{2}{*}{ mouse } \\
\hline & & Aldh1L1 & \\
\hline
\end{tabular}

\subsection{Microscopy and Blinded Colocalization Analysis}

Control and stained specimens were completely screened, and cells were documented using an upright microscope (Axioskop 2, Zeiss, Oberkochen, Germany) equipped with halogen illumination (HA 100, Zeiss) and narrow-band fluorescence filter sets (472/30/495 DC mirror/513/17 (green channel), 560/25/585/620/60 (red channel), and 406/15/425/460/50 (blue channel)). Images were taken at $10 \times, 20 \times($ Plan-apo), or $100 \times($ N.A. 1.3, oil) using a $2048 \times 2048$ pixel monochrome camera (Spot Insight 4, Diagnostic Instruments, Sterling Heights, MI, USA) with $7.45 \mu \mathrm{m}$ square pixels and 14 bit sampling depth (CCD chip type KAI 4021). Channel overlay was performed at the step of image acquisition using the software Spot 5.0 Advanced (SPOT Imaging Solutions, Diagnostic Instruments), at the same time correcting for chromatic aberration [26].

Uneven image illumination was flattened applying the "rolling ball" algorithm (at 500 pixel radius) as implemented in ImageJ [27]. Background was adjusted on the basis of the control staining, and identically for all frames from a given staining, using Adobe Photoshop. For presentation, brightness and color were adapted to represent the microscope image. Only global, non-selective, and linear image operations were carried out. In some frames of Rab6A/NeuN-stained specimens (see Figure S9), deconvolution was applied to further increase image clarity and resolution, using a motorized microscope (Zeiss Cell Observer) and a CCD (Sony IXC285AL) with $6.45 \mu \mathrm{m}$ square pixels. Stacks of 60 images were acquired at $50 \mathrm{~nm}$ spacing and $100 \times$ final magnification $(63 \times 1.4$ N.A. $\times 1.6 \times)$. The image stacks were deconvolved applying calculated point spread functions (PSFs) and iterative deconvolution (Volocity Software (Quorum Technologies Inc., Puslinch, ON, Canada)). Quantitation of cellular colocalization was blinded to reduce bias for cell morphology and cell type. In double and triple labellings, a reference population was determined corresponding logically to the issue, e.g., to investigate the proportion of $\mathrm{Rab} \mathrm{A}^{+}$microglial cells, the reference population was $\mathrm{Iba}^{+}$, not vice versa. Of the 2 or 3 color channels, all except that of the reference population were rendered invisible in Photoshop. A large number of cells appearing "complete" (with obvious soma, nucleus (presumed, if not stained), and stem processes in the section plane) were first dot-marked on a transparent "overlay" (in Photoshop, see Figure S1). In a second step, the channel to be examined was re-opened for colocalization. Only the dot-marked cells were checked for cellular anti-gen colocalization to finally obtain the percentage of $\mathrm{Rab} \mathrm{A}{ }^{+} / \mathrm{Iba}^{+}$microglial cells. In some cases, double and triple labellings were repeatedly examined with different reference populations, to study different questions. 
Assessing colocalization at the level of cross-sectioned soma and nucleus largely precludes false positive colocalization by superimposition in 3D. Firstly, absence of tissue permeabilization, as in our protocol, results in antibody penetration depth of less than $1 \mu \mathrm{m}$. Also, cells below the section surface can only be labelled intracellularly if continuous with a process physically cut by tissue sectioning; the plethora of small astrocytic processes exposed at the section surface are too narrow to provide antibody access to deeper structures. Second, with a depth of focus of approximately $500 \mathrm{~nm}$ (100× objective), and an established astrocyte nucleus size of 5-6 $\mu \mathrm{m}$, spurious superimpostion of the Rab6 $\mathrm{A}^{+}$ section surface and a deeper cell soma is highly improbable. In this context, we did not observe Rab6 $\mathrm{A}^{+}$cell nuclei. In summary, the images examined for colocalization represent labelling at the cell surface, in a focal plane approximately $500 \mathrm{~nm}$ thick.

Distribution of Rab6 $\mathrm{A}^{+}$in astrocytes and other cells was assessed qualitatively by structural analysis of "complete cells" in the cortex, corpus callosum, hippocampus, and thalamus, imaged at $100 \times$, altogether 14.568 astrocytes in 1774 frames, from 3 mice. For quantitative assessment, morphometric object-oriented image analysis was performed on regions-of-interest (ROIs) of 10 representative cells each from the 4 types found and classified qualitatively. Using particle analysis and planimetry commands in Image [27], we determined individual area and number of Rab6 $\mathrm{A}^{+}$objects.

\section{Results}

\subsection{Rab6A is Massively Present All Over the Brain}

At low magnification, Rab6A staining in mouse brain sections is abundant and diffuse in all areas of forebrain and brainstem, resembling background staining. Autofluorescence in sections reacted without primary antibody is considerably weaker (Figure 1A,C,E) so that Rab6A staining, e.g., in cortex, hippocampus, septum (Figure 1B,D,F), and other regions (e.g., hypothalamus, cerebellum, amygdala, thalamus; Figure S2) is regarded as signal, including white matter (Figure 1B). Signal intensity varies between gray and white matter, and across layers (Figure 1B,D,F). Processes and fluffy patches (arrows) suggest astrocyte territories; moreover, blood vessels (asterisks) are clearly outlined (Figure 1B,D).

\subsection{Localisation of Rab6A in Astrocytes}

At higher magnification, Rab6A staining is grainy, however, not homogeneous, but with "rings" and "alleys", presumably negatively outlined neuronal dendrites in crossand longitudinal section (Figure S3A,C). Rab6A ${ }^{+}$labelling, e.g., in hippocampus, indicates preferential labelling of astroglial structures, with stem processes of fibrous astrocytes in white matter (Figure S3B), labelling of ependymocytes (Figure S3A), vascular outlines in the hippocampal fissure (Figure S4A), and encircling of the granule cells (Figure S4B). Continuous and intense cellular label was seen in the subgranular zone of the fascia dentata, where the cells labelled may be subgranular astrocytes and/or stem cells (Figure S4).

Astrocyte labelling could be substantiated in sections double stained for Rab6 A and GFAP (Figure S5). Examining GFAP ${ }^{+}$astrocytes at high resolution, we found that Rab6 ${ }^{+}$ structures interestingly appear as puncta or clusters of puncta. They are partly juxtaposed with $\mathrm{GFAP}^{+}$main processes and somata (Figure 2). Rab6A $\mathrm{A}^{+}$structures also appear to fill the numerous $\mathrm{GFAP}^{-}$peripheral astrocyte processes (PAPs) known to emerge from the main processes and to make up the diffuse label at low power (Figure 1B,D and Figure $\mathrm{S} 1 \mathrm{~A}, \mathrm{C})$. Rab6A $^{+}$puncta may also be localized in the perivascular glial endfeet (Figure S6). 


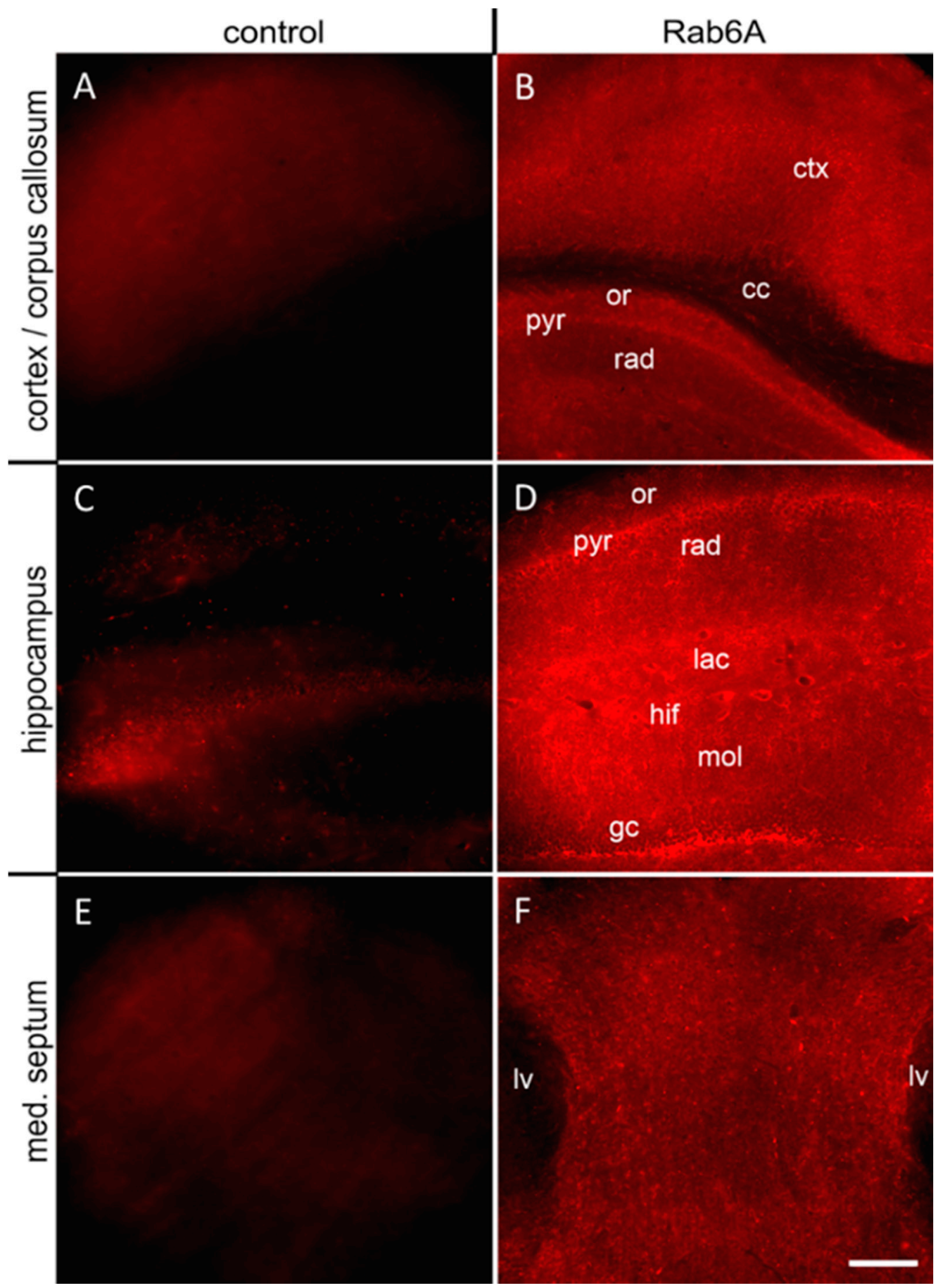

Figure 1. Rab6A is massively present all over the brain. In relation to the corresponding controls reacted without primary antibody $(\mathbf{A}, \mathbf{C}, \mathbf{E})$, specific immunostaining of mouse tissue sections showed massive, uniform, and ubiquitous presence of Rab6A in all brain regions investigated; including (B) cortex with corpus callosum, (D) hippocampus, (F) medial septum. Note blood vessels in hippocampal fissure (hif). cc, corpus callosum; ctx, cortex; gc, granule cell layer; hif, hippocampal fissure; lac, stratum lacunosum-moleculare; med. septum, medial septum; mol, molecular cell layer; or, stratum oriens; pyr, stratum pyramidale; rad, stratum radiatum. Scale (in F, for A-F): $50 \mu \mathrm{m}$. 

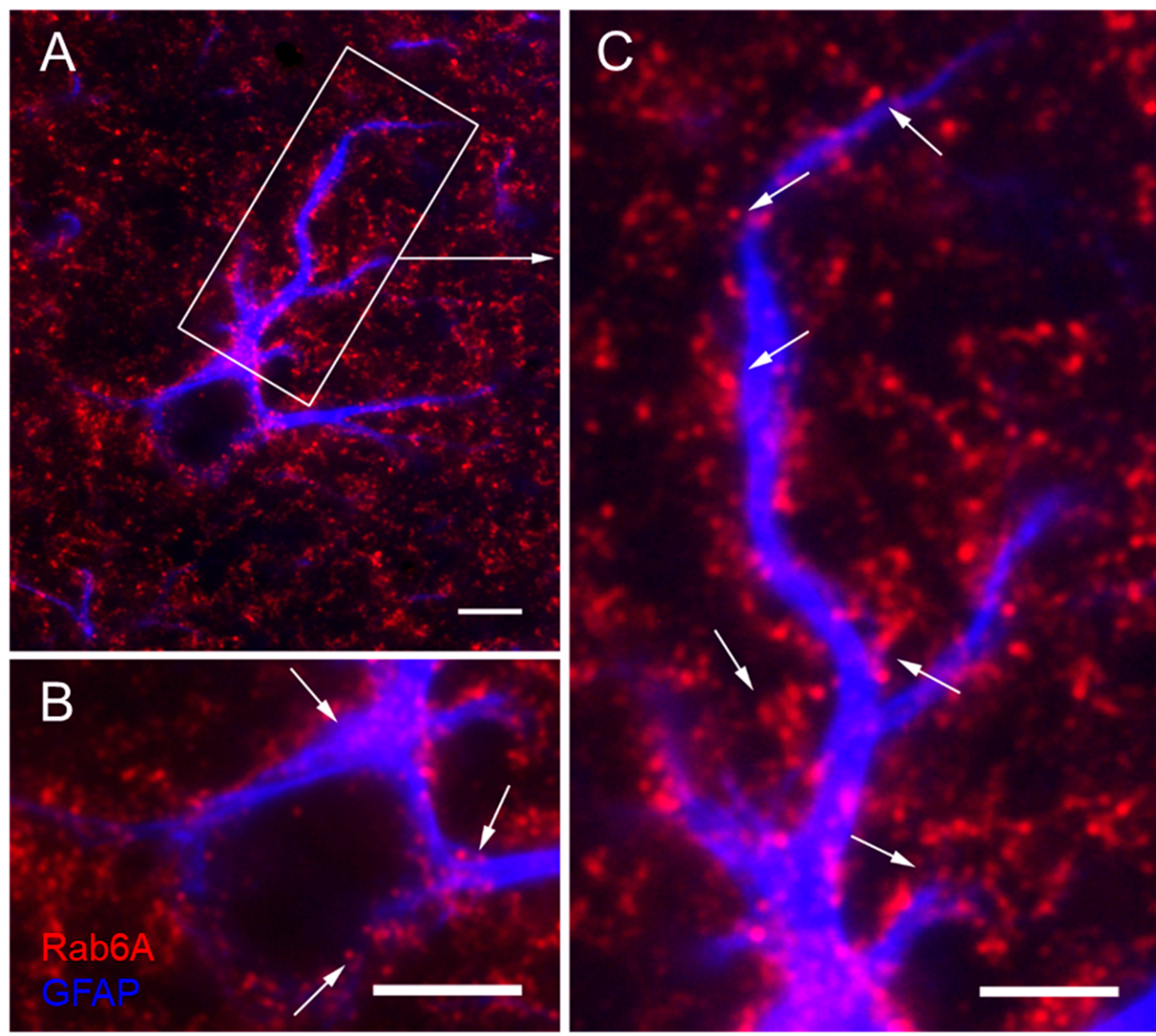

Figure 2. Morphology and subcelluar distribution of Rab6A in glial fibrillary acid protein (GFAP) ${ }^{+}$ astrocytes. Countless Rab6 ${ }^{+}$grains (A) resolve to single puncta or chains of puncta at higher magnification $((\mathbf{B}, \mathbf{C})$, from $(\mathbf{A}))$ that may be associated with $\mathrm{GFAP}^{+}$processes $(\mathbf{A})$ or soma (arrows in (B)). Rab6A ${ }^{+}$chains of puncta appear to fill the $\mathrm{GFAP}^{-}$fine processes that are connected to the main processes (arrows in (C)). Hippocampus, stratum radiatum of CA1. Scale: $5 \mu \mathrm{m}(\mathbf{A}, \mathbf{C}), 3 \mu \mathrm{m}(\mathbf{B})$.

\subsection{Rab6A is Contained in All Astrocytes}

Blinded colocalization quantitation in $\mathrm{GFAP}^{+}$astrocytes in hippocampus, thalamus, cortex, and corpus callosum showed that $100 \%$ of GFAP ${ }^{+}$astrocytes also display Rab6A staining (Diagram S1), demonstrating that $\mathrm{GFAP}^{+} / \mathrm{Rab} \mathrm{A}^{+}$astrocytes do not represent a subpopulation of $\mathrm{GFAP}^{+}$astrocytes.

It is long established that only a varying proportion of astrocytes display GFAP, in a region-dependent manner [28]. To examine whether all astrocytes or only the GFAP ${ }^{+}$ or other subpopulation displays Rab6A labelling, we combined Rab6A or Rab6A/GFAP staining with immunolabelling for one of three accepted pan-astrocytic markers, i.e., markers present in all astrocytes (Table 3), v.z. GS [29], Aldh1L1 [30,31], or SOX9 [32]. In blinded analysis, all $\mathrm{GFAP}^{+} / \mathrm{Rab} \mathrm{A}^{+}$astrocytes were co-labelled for the pan-astrocytic markers GS or Aldh1L1 (Figure 3, Diagrams S3, S4). Using only double labellings and reversing the reference population, we found that $100 \%$ of the cells labelled with the panastrocytic markers GS, Aldh1L1, or Sox9 are positive for Rab6A (Table S1A; Figures 4 and S7; Diagrams S2, S5, and S6). 
Since there is some debate as to the validity of GS or Aldh1L1 as pan-astrocytic markers, we quantitatively assessed the same material with different reference populations. Thus, we studied the proportion of $\mathrm{GFAP}^{+}$astrocytes either in $\mathrm{GS}^{+} / \mathrm{Rab}^{+} \mathrm{A}^{+}$astrocytes or Aldh1L1 ${ }^{+} /$Rab6A $^{+}$astrocytes. GFAP co-staining varies in a region-dependent way that is similar in both triple stainings, i.e., with $\mathrm{GS}^{+} / \mathrm{Rab}^{+} \mathrm{A}^{+}$and Aldh1 $11^{+} / \mathrm{Rab} \mathrm{A}^{+}$. While all $\mathrm{GS}^{+} / \mathrm{Rab}^{+} \mathrm{A}^{+}$or Aldh1L1+ ${ }^{+} / \mathrm{Rab}^{+} \mathrm{A}^{+}$astrocytes in the corpus callosum (fibrous astrocytes) and in the hippocampus display GFAP label, only $58 \%$ and $26 \%$ of the $\mathrm{GS}^{+} / \mathrm{Rab}^{+} \mathrm{A}^{+}$ astrocytes were $\mathrm{GFAP}^{+}$in cortex and thalamus, respectively (Diagram S7), and 24\% and $14 \%$ of the Aldh1L1 ${ }^{+} /$Rab6A $^{+}$astrocytes (Diagram S8).
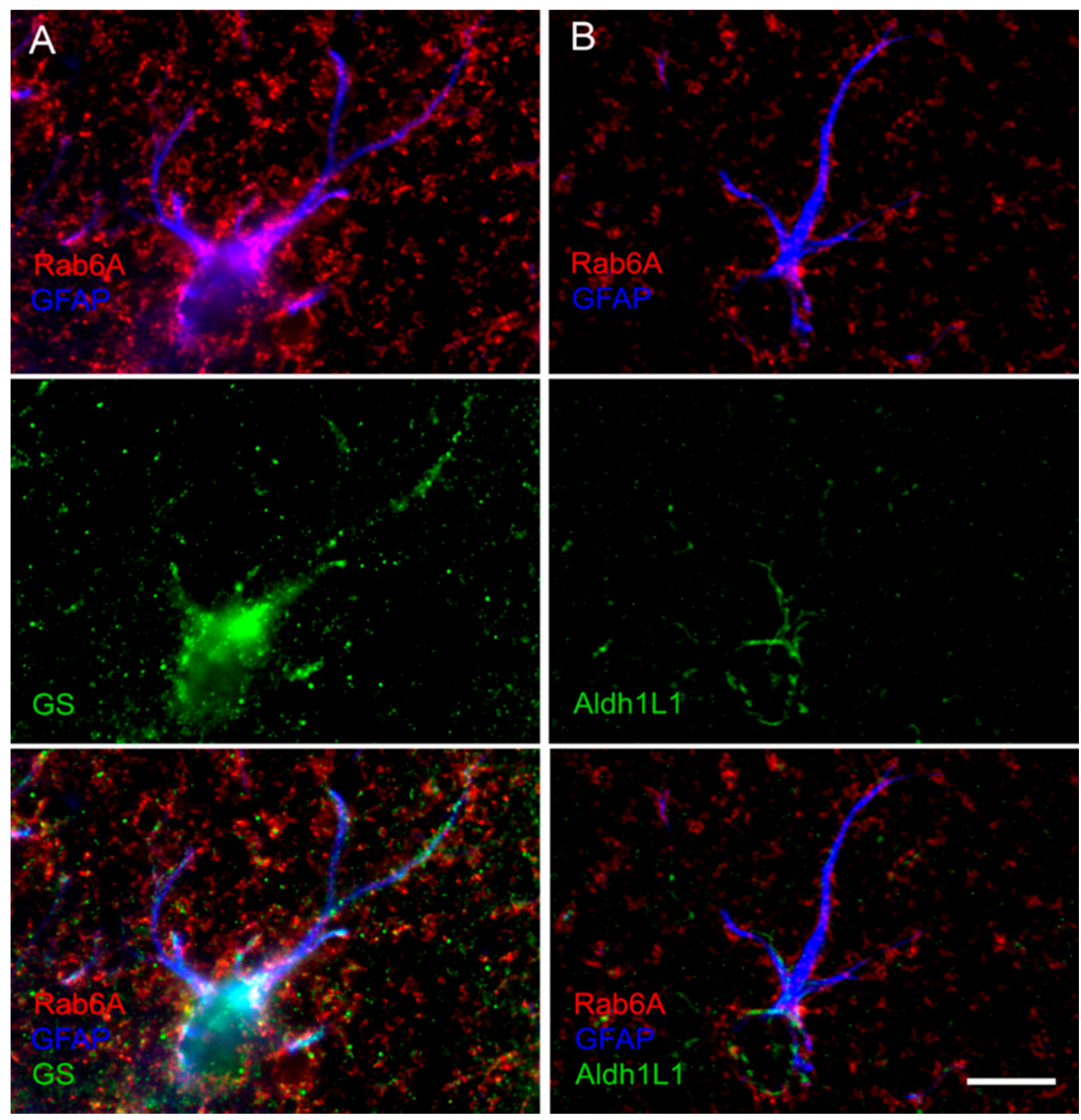

Figure 3. Glutamine synthetase (GS) and aldehyde dehydrogenase 1 family member L1 (Aldh1L1) are localized in all $\mathrm{GFAP}^{+} / \mathrm{Rab}^{+}$astrocytes. All GFAP ${ }^{+} / \mathrm{Rab}^{+}$astrocytes assessed for either GS or Aldh1L1 were triple-stained (see Diagrams S7 and S8). Note the pronounced punctate GS/Rab6A double staining in the abundant GFAP ${ }^{-}$peripheral processes ((A), merge). This is less pronounced in triple staining with Aldh1L1 (B), where labelling is distinct in soma. Hippocampus, stratum oriens (A), and radiatum (B). Scale: $10 \mu \mathrm{m}$ (for (A,B)). 


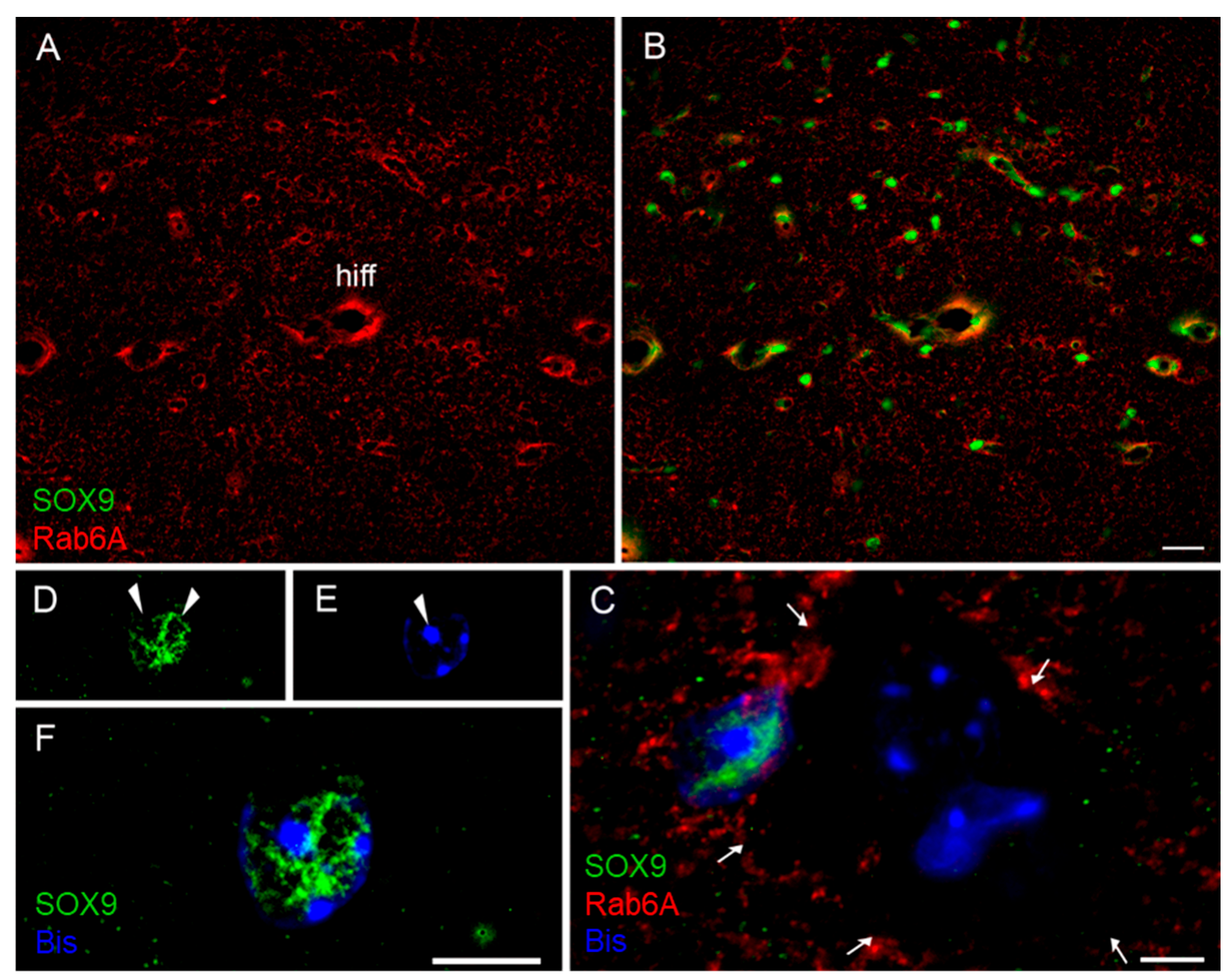

Figure 4. All Sox $9^{+}$cells are Rab6 $\mathrm{A}^{+}$. All openings for nucleus visible in Rab6A staining (A) are filled by SOX9 staining (B) (for quantitation, see Diagram S2). (C) The nucleus of a neuron demarcated by Rab6 $\mathrm{A}^{+}$glial processes (arrows) is SOX9whereas that of a perineuronal astrocyte is SOX9 ${ }^{+}$. Within astrocyte nuclei, gaps in SOX9 label ((D), arrowheads) and heterochromatin $((\mathbf{E})$, bisbenzimidine, arrowheads) are complementary (F). hiff, hippocampal fissure; Bis, bisbenzimidine. Scales: $50 \mu \mathrm{m}$ (for $(\mathbf{A}, \mathbf{B})), 5 \mu \mathrm{m}(\mathbf{C}, \mathbf{F})$.

In summary, the double stainings showed that all astrocytes, as defined by labelling for GS, Aldh1L1, or SOX9, display Rab6A in the regions studied. Moreover, the GFAP ${ }^{+}$ subpopulation of astrocytes represents a region-dependent fraction of the Rab6 $\mathrm{A}^{+}$astrocyte population, which parallels the established relation of the $\mathrm{GFAP}^{+}$and $\mathrm{GS}^{+}$astrocytes $[28,33]$.

\subsection{Rab6A is an Astrocyte-Specific Marker}

Studying the morphology of Rab6A staining, it appears that Rab6A labels astrocytes only. To verify this, we evaluated microglial cells, oligodendrocytes, NG2-glial cells, and neurons for potential Rab6A labelling in sections double labelled for the cell type-specific markers Iba1, CNPase, NG2, and NeuN, respectively. The non-astrocytic cells constituted the reference population in blinded analysis. All cell types were sampled from cortex, and oligodendrocytes also from corpus callosum and hippocampus; cell numbers are given in Table S1B. Neurons were not counted. Depending on secondary antibody, there was false positive Rab6A staining selectively in microglial cells (1-3 larger granula in many cells) present also in the controls (see Figure S8). Only with biotinylated horse anti-goat (followed by CY3-conjugated streptavidin) and donkey anti-mouse Alexa 647 was this non-specific, selective staining prevented. Virtually all non-astrocytic cells examined are negative for Rab6A: 99\% of NG2 cells; $100 \%$ of microglia; and $98.3 \%$ of oligodendrocytes 
from cortex, 99.5\% from corpus callosum, and 100\% from hippocampus (Figure 5), and no Rab6A ${ }^{+}$neurons were found (Figure S9).
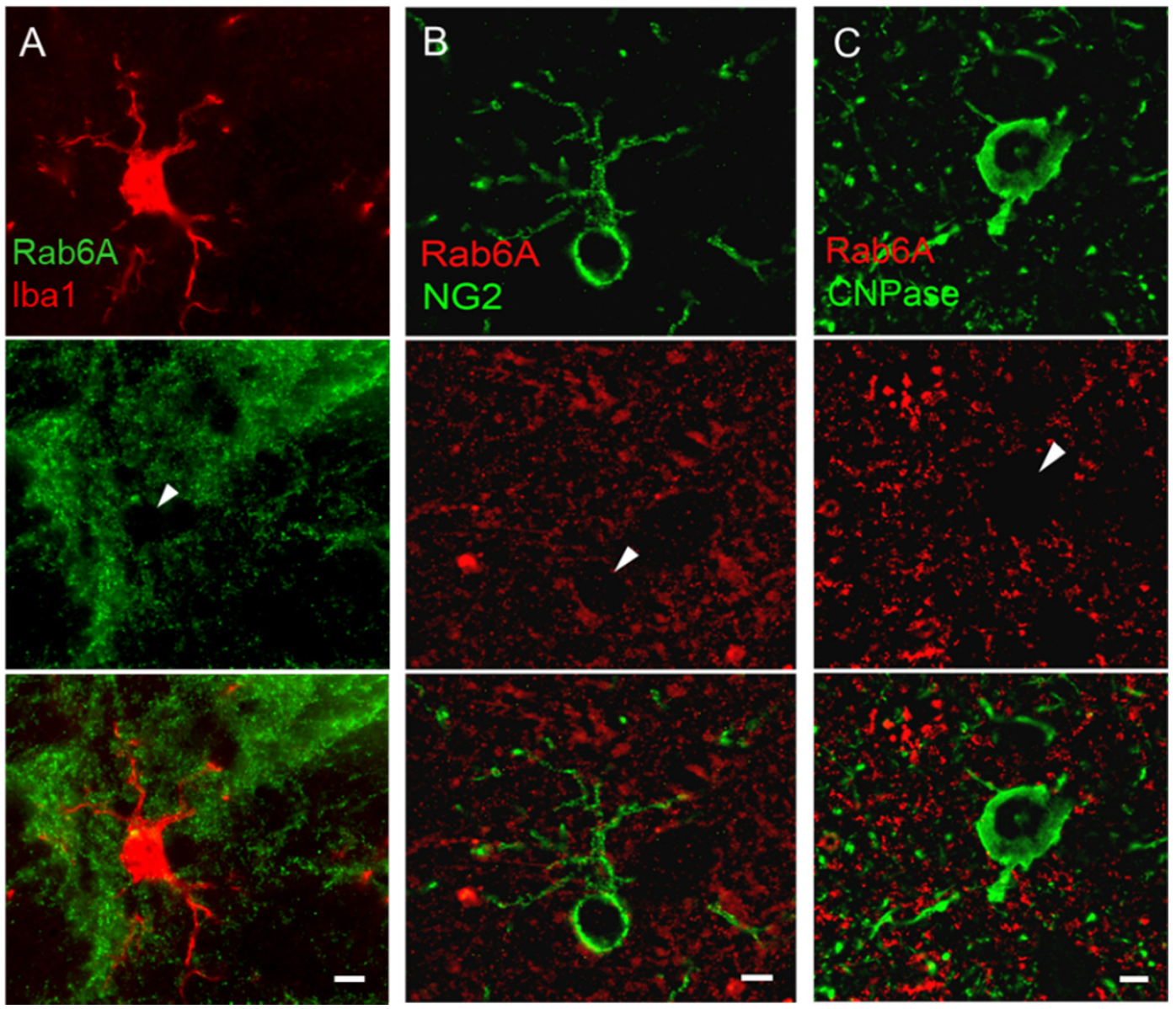

D

Colocalization of glial cell types with Rab6A

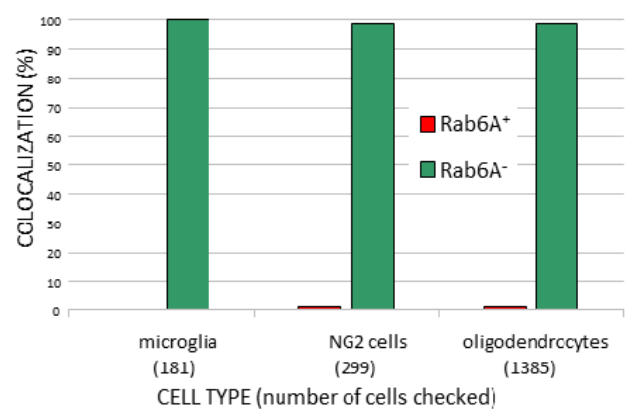

Figure 5. Rab6A is specifically associated with astrocytes. In blinded colocalization analysis in preselected cells stained for Iba1 ((A) microglia), NG2 ((B) NG2 cells), or CNPase ((C) oligodendrocytes), nearly all cells are gaps in the Rab6A channel (arrowheads in (A-C)), and Rab6A- in double staining (bottom row). (D) Quantitation of Rab6A localization glial cell types. Scales: $10 \mu \mathrm{m}(\mathbf{A}), 5 \mu \mathrm{m}(\mathbf{B}, \mathbf{C})$.

\subsection{Morphology and Subcellular Distribution of Rab6 ${ }^{+}$Puncta}

At high magnification, Rab6 $\mathrm{A}^{+}$grains are pleomorphic, and their shape is mostly round and elongated; frequently they are contiguous, thus adding to their overall complex structure (Figure 2C). The smallest Rab6 $\mathrm{A}^{+}$structures are at the light microscopic detection 
limit and are highly abundant, resulting in a "salt and pepper" appearance (Figure 6A-C). As evident in GFAP double staining, the majority of Rab6 $\mathrm{A}^{+}$grains predominantly fill the PAPs but are also aligned along the $\mathrm{GFAP}^{+}$stem processes (Figure 6A-C). However, the subcellular distribution, grain size, and number vary from one cell to the other. For descriptive reasons, we divided astrocytes into four types (I-IV) on the basis of their subcellular distribution, morphology, number, and size of Rab6 $\mathrm{A}^{+}$structures within the individual cell. The types are described and illustrated in Table 4 and Figure 6, respectively. This classification was confirmed by significant differences in object-oriented morphometry (Figure S10). The Rab6A ${ }^{+}$grain size in area units $\left(\mu \mathrm{m}^{2}\right.$; Table 4$)$ is meant to illustrate only relative size, since the actual size of the smaller grains is at the limit of light microscopic resolution and is considered subject to nonlinear distortion.

As a general observation, the number of Rab6 $\mathrm{A}^{+}$puncta successively decreases from types I-IV, and they become more "centralized" in the perinuclear cytoplasm, while concomitantly, their size increases, with a pronounced increase in type IV (Figures 6A-D and $\mathrm{S} 6 \mathrm{E}, \mathrm{F})$. These astrocyte types I-IV are not region-specific, and their relative frequencies in the thalamus and telencephalon decrease from I-IV (Figure 6E). The distribution of types I-IV within tissue appears scattered and random, and there are no accumulations, and there is no predominant localization with respect to layers, the pial surface, vessels, neurons, or white matter.

\subsection{Rab6A is Also Contained in Human Astrocytes}

We tested the validity of the observations in mouse brain for the human. Freshly fixed human cortex was obtained from three patients during epilepsy surgery (see Table 1) and labelled for Rab6A or Rab6A/GFAP. Like in mouse brain sections, the Rab6A signal is above background autofluorescence, which shows as an even stain all over the section at low magnification, and is granular at high magnification. In Rab6A/GFAP double staining, Rab6A is clearly localized in astrocytes, predominantly in their stem and peripheral processes, where it is frequently clustered, appearing as bunches of grapes (Figure 7).

We applied the classical morphological criteria, v.z. hypertrophy of soma and main processes, as well as GFAP overexpression, as a working definition of reactive astrocytes in human, although it is widely accepted now that astrocyte reactivity is a complex and heterogeneous phenomenon comprising changes in morphology, gene expression, signaling, and proliferation [34]. Thus, both non-reactive and reactive astrocytes were observed to varying degrees in tissues from patient cases I and II, which were diagnosed focal cortical dysplasia (see Table 1). Exclusively non-reactive astrocytes were seen in the cortex tissue removed for surgical access in patient case III (ganglioglioma in hippocampus). Double staining was blindly quantitated with GFAP as the reference channel, examining separately non-reactive and reactive astrocytes. All non-reactive astrocytes examined in cases I-III were Rab6 $\mathrm{A}^{+}$; of the reactive astrocytes studied, $100 \%$ of case II and $88 \%$ of case I were Rab6 $\mathrm{A}^{+}$, leaving $12 \%$ of Rab6 $\mathrm{A}^{-}$astrocytes (Figure S11).

We further studied whether the classification of mouse astrocyte types based on Rab6A ${ }^{+}$grain number, size, and distribution within the individual cell is reflected in human astrocytes. In the reactive and non-reactive astrocytes studied, the astrocyte types I-IV were similarly observed and classified, and were found at varying relative frequencies (Figure S12). In summary (Figure S12E), relative frequencies in cases I-II did not stepwise decrease over types I-IV, as found in mouse astrocytes. This was the case only in the cortex tissue from case III, which can be assumed not to display pathological alterations, and did not contain reactive astrocytes. In the cortex from patient cases I and II, there was no consistent correlation between the frequencies of types I-IV and reactive vs. non-reactive astrocytes (Figure S12E). As in mouse brain, the distribution of astrocyte types I-IV in human cortex tissue appears random; there is no predominant localization with respect to structural features, cortical layers, the pial surface, vessels, or neurons. 

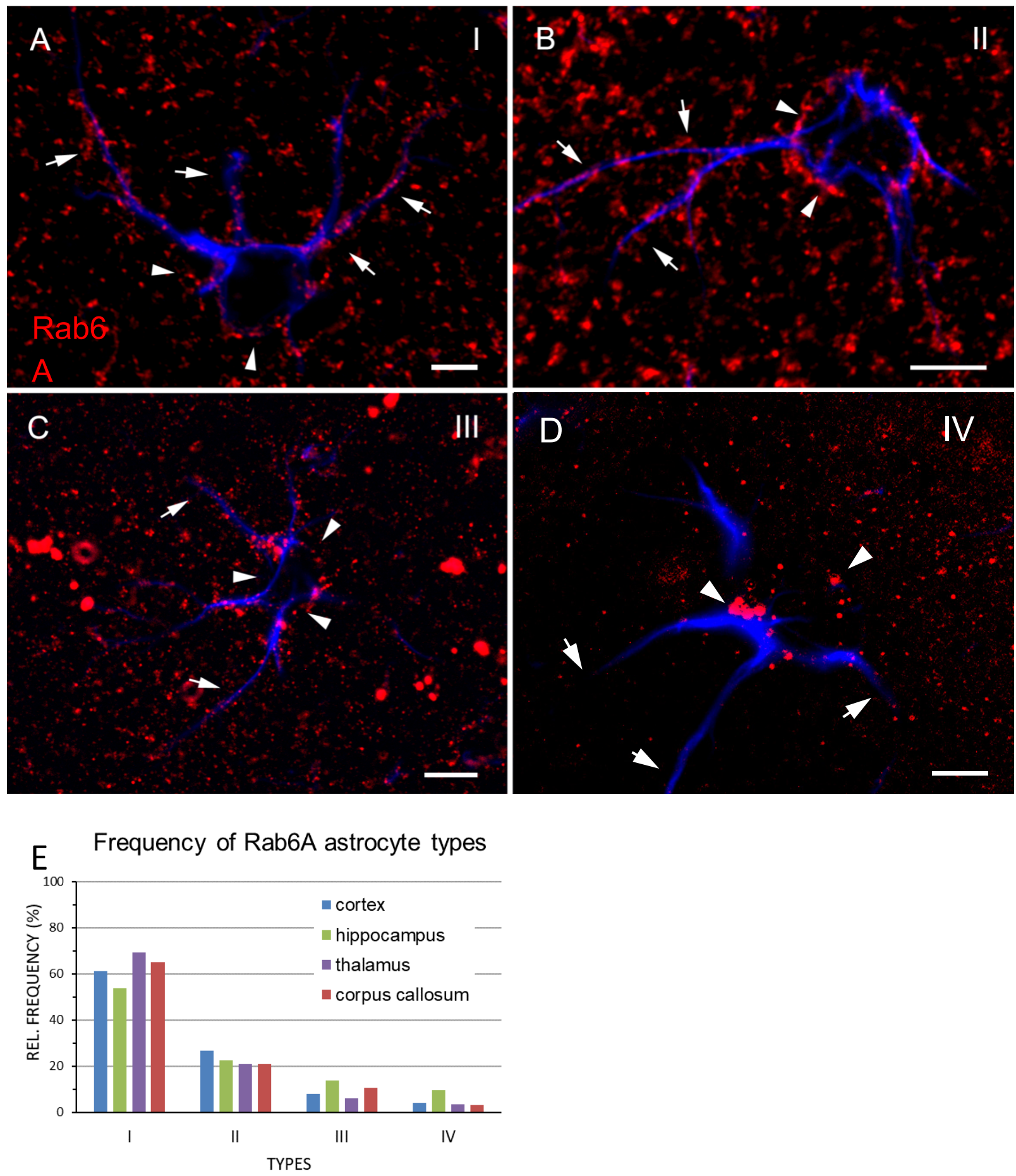

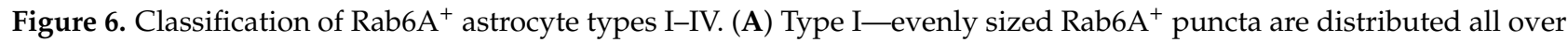
the perinuclear region (arrowheads) and in stem and peripheral processes (arrows). (B) Type II-Rab6 $\mathrm{A}^{+}$puncta in the perinuclear region (arrowheads) and in stem and peripheral processes (arrows) vary in size and may occur in clusters. (C) Type III-There is irregular distribution and high variability in size of Rab6 $\mathrm{A}^{+}$puncta in the perinuclear region (arrowheads). In stem and peripheral processes (arrows), Rab6 $\mathrm{A}^{+}$puncta are evenly but sparsely distributed. (D) Type IV-the perinuclear region contains Rab6 $\mathrm{A}^{+}$puncta of highly varying size occurring in clusters, mostly on one side of the nucleus (arrowheads). Hardly any Rab6 $\mathrm{A}^{+}$puncta are present in the processes (arrows). (E) Relative frequencies of types I-IV; percentage values refer to 100\% of each type. Scales: $5 \mu \mathrm{m}(\mathbf{A}, \mathbf{D}), 10 \mu \mathrm{m}(\mathbf{B}, \mathbf{C})$. 
Table 4. Classification of astrocyte types I-IV—subcellular distribution, morphology, number, and size of Rab6A ${ }^{+}$grains within the individual cell.

\begin{tabular}{|c|c|c|}
\hline Type & Morphology, Number, and Size of Rab6A ${ }^{+}$Grains & Subcellular Distribution \\
\hline I & $\begin{array}{ll}\text { - } & \text { evenly sized } \\
\text { - } & \text { mean area: } 2.5 \mu \mathrm{m}^{2} \\
\text { - } & \text { mean number } * 123\end{array}$ & $\begin{array}{l}\text { - } \quad \text { evenly distributed all over the cell } \\
\text { - } \quad \text { present in perinuclear cytoplasm, stem processes, } \\
\text { PAPs } \\
\text { - } \quad \text { at the cell boundary, throughout the glial territory }\end{array}$ \\
\hline II & $\begin{array}{ll}- & \text { heterogeneous size } \\
- & \text { mean area: } 3.0 \mu \mathrm{m}^{2} \\
- & \text { mean number } *: 104\end{array}$ & $\begin{array}{l}\text { - } \quad \text { partly appearing in clusters } \\
\text { present in perinuclear cytoplasm, stem processes, } \\
\text { PAPs } \\
\text { - } \quad \text { at the cell boundary, throughout the glial territory }\end{array}$ \\
\hline III & $\begin{array}{l}\text { - } \quad \text { size of grains in perinuclear cytoplasm or at the cell } \\
\text { boundary may be double or multiple of those nearby } \\
\text { - } \quad \text { evenly sized in stem processes, PAPs } \\
\text { - } \quad \text { mean area: } 2.6 \mu \mathrm{m}^{2} \\
\text { - } \quad \text { mean number } * 70\end{array}$ & $\begin{array}{l}\text { - } \quad \text { uneven distribution in perinuclear cytoplasm and at } \\
\text { cell boundary } \\
\text { - } \quad \text { evenly distributed in stem processes and PAPs } \\
\text { - } \quad \text { may be only sparsely present in processes }\end{array}$ \\
\hline IV & $\begin{array}{ll}\text { - } & \text { large size, lumps } \\
\text { - } & \text { mean area: } 4.3 \mu \mathrm{m}^{2} \\
\text { - } & \text { mean number } * 9\end{array}$ & $\begin{array}{l}\text { - } \quad \text { organized in cluster(s) on one side of nucleus } \\
\text { - } \quad \text { sparsely present if at all, in stem processes and PAPs, } \\
\text { thus hardly present throughout the glial territory }\end{array}$ \\
\hline
\end{tabular}

${ }^{*}$ number of Rab6A+ puncta/ROI (see Figure S10).
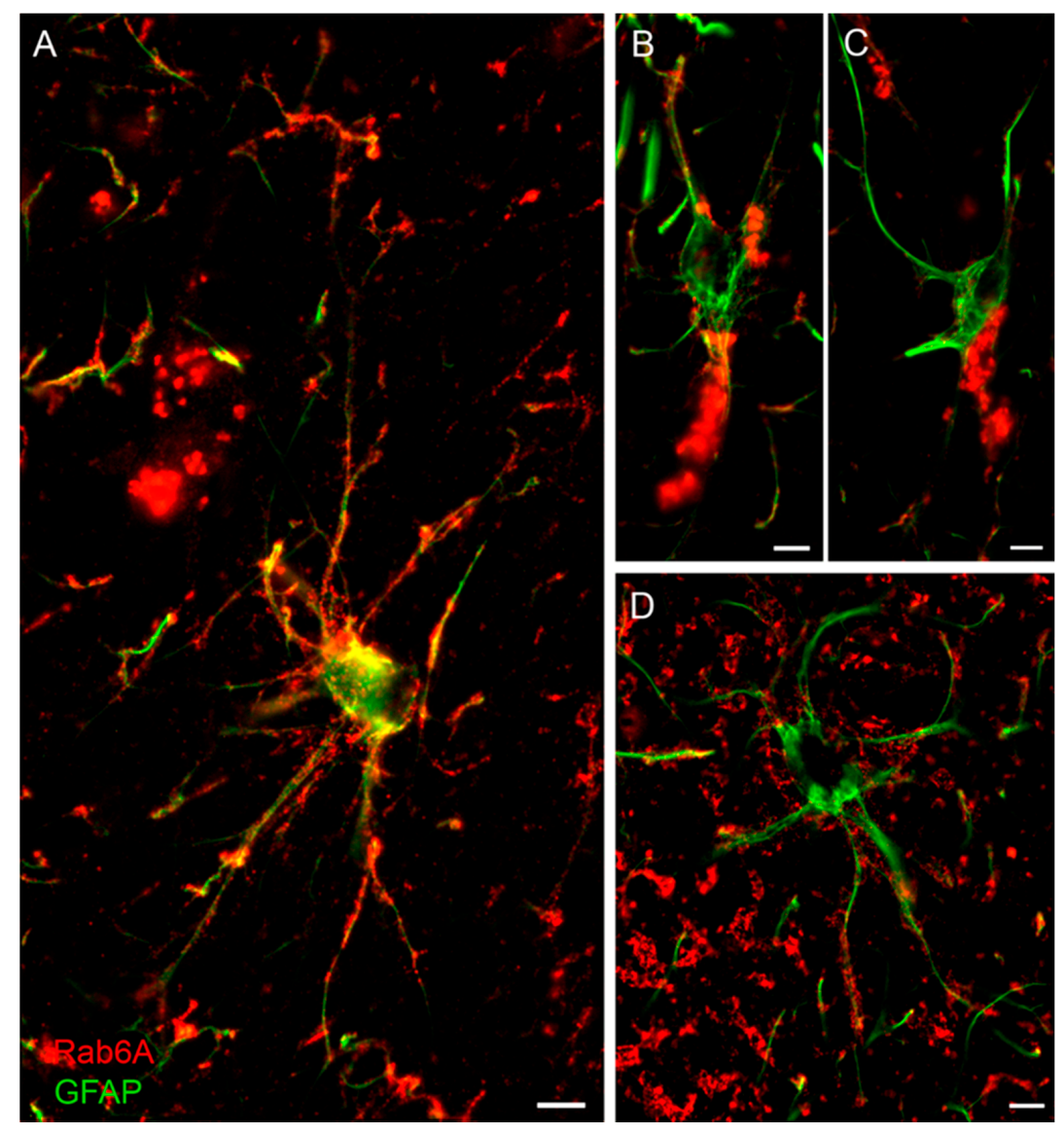

Figure 7. Rab6A in human GFAP ${ }^{+}$astrocytes. (A-D) Examples from three cases. All of the preselected human nonreactive $\mathrm{GFAP}^{+}$astrocytes and most of the reactive $\mathrm{GFAP}^{+}$astrocytes were Rab6A+ (for quantification, see Figure S11E). Note variability of cellular Rab6A staining with pronounced label in the distal processes (A,D) or predominant staining in the perinuclear region (B,C). Scales: $10 \mu \mathrm{m}(\mathbf{A}, \mathbf{D}), 3 \mu \mathrm{m}(\mathbf{B}), 5 \mu \mathrm{m}(\mathbf{C})$. 


\section{Discussion}

\subsection{Astrocyte Heterogeneity and Cell Type Specificity}

All analyses of cellular co-localization carried out here were not by general impression but by blinded and quantitative assessment of a representative number of individual cells. As a major finding of this study, Rab6A is selectively and specifically localized in astrocytes.

First, Rab6A could not be detected in neurons or any of the other glial cell types investigated (microglia, oligodendrocytes, NG2 cells) by double-immunostaining using well-established markers (NeuN, Iba1, CNPase, and NG2).

Second, a series of mutually confirming colocalization studies led to the conclusion that all astrocytes are positive for Rab6A, particularly in the light of extant data on GS and Aldh1L1 labelling. In spite of some studies reporting presence of GS in non-astrocytic cell types, GS may be considered the most inclusive and specific astrocyte marker $[28,29]$. Aldh1L1 was first described as an astrocytic marker (immunocytochemistry [31]), and this was extended to specific, pan-astrocytic labelling by transcriptome analysis of Aldh1L1expressing cells [30] using BAC ALDH1L1 eGFP mice. A minor Aldh1L1 ${ }^{+}$subpopulation of oligodendrocytes observed by Yang et al. [35] in the same BAC ALDH1L1 eGFP mice had been excluded by Neymeyer et al. [31] and Cahoy et al. [30]. Analyzing double stainings for Rab6A/GS and Rab6A/Aldh1L1, and using alternate reference populations, all Rab6 ${ }^{+}$ cells were $\mathrm{GS}^{+}$and Aldh1 $11^{+}$, and there were no GS${ }^{+}$or Aldh1L1 $1^{+}$single-stained cells. This confirms the congruence of $\mathrm{GS}^{+}$and Aldh1 $11^{+}$populations, at the same time establishing that Rab6A is a pan-astrocytic marker.

There is general consensus that both GS and Aldh1L1 stain more astrocytes than GFAP, in a region specific manner [28-31,36]. This is in line with the expression of GS or Aldh1L1 in all regions examined here, in $100 \%$ of the $\mathrm{GFAP}^{+} / \mathrm{Rab}^{+} \mathrm{A}^{+}$cells. Similarly, only a fraction of $\mathrm{GS}^{+} / \mathrm{Rab} \mathrm{A}^{+}$or Aldh1L1 ${ }^{+} / \mathrm{Rab} \mathrm{A}^{+}$astrocytes examined were $\mathrm{GFAP}^{+}$in the cortex and thalamus, thus further confirming extant data and the most inclusive labelling of astrocytes by Rab6A. In addition, the Rab6A/SOX9 double staining would further confirm both the recent introduction of SOX9 as a specific pan-astrocytic marker [32] and the conclusion of Rab6A as such a marker.

Consulting published CNS transcriptome analyses [30,37-39] for cell type-specific $R A B 6 A$ expression yields ambiguous results. Rab6 may be present in its main isoforms Rab6A and Rab6B, but these transcriptome studies are based on RNA chips that do not specifically address $R A B 6 A$ transcription; they apply one sequence for $R A B 6 B$, and another one designated " $R A B 6$ ", which we assume is non-discriminatory. However, the transcriptome data permit to concluded that the $R A B 6 B$ gene is hardly expressed in astrocytes if at all [30,39], in line with Doyle et al. [37], who could not detect $R A B 6 B$ expression in astrocytes. Further, $R A B 6 B$ expression has been found to be mainly neuronal, since only neurons were consistently positive with the several Rab6 probes used [30], a finding confirmed by the analysis by Zhang et al. [39], and the view that in the CNS, RAB6B is the neuronal isoform $[20,25]$. Thus, while these transcriptome analyses do not specifically confirm the present data, they also do not contradict them.

The Rab6A monoclonal antibody (clone 3G3) used here is raised against a C-terminal peptide with a sequence present only in the Rab6A but not the Rab6B isoform. Its intracellular staining pattern with the dense peri- or juxtanuclear cisterns, vesicles, and radiating puncta described here is typical of distal Golgi cisterns, the TGN, and TGN-derived organelles. In the field of cell biology, this Rab6 pattern is established without debate in numerous cell lines and studies, using other anti-Rab6 antibodies or fluorescent fusion proteins (e.g., [23,24,40], reviewed in [20]). The Rab6A antibody applied here has previously replicated this typical vesicular perinuclear staining in Chinese hamster ovary $(\mathrm{CHO})$ cells [41]. To our knowledge, however, immunocytochemical localization of Rab6A or B in mammalian tissues has been determined only by very few studies (e.g., [25,39,41-43], see above), including the present one.

Our study is the first to systematically investigate cell type-specific localization of Rab6A in the CNS. Previous CNS data on Rab6 in general are sparse and not very con- 
clusive. Thus, Huang et al. [44] demonstrated immunolocalization and light-dependent expression of Rab6 in mouse and rat retina. Applying colabelling for GS, the authors concluded that Rab6 is not localized in the GS ${ }^{+}$Müller cells, without supplying an alternative, although we find that their data would not exclude Müller cells. Studies of Rab6 expression by immunostaining and immunoblot in hippocampus and cortex from patients diagnosed with Alzheimer's disease revealed pronounced signal in neurons [45]. The polyclonal antibody (anti-Rab6, Santa Cruz) used in that study recognizes all Rab6 isoforms, however, it detects Rab6B at a much lower concentration (1:2000) than Rab6A (1:50) (Derouiche, unpublished). Since Rab6B is regarded as the neuronal isoform $[20,25]$, it can be assumed that Scheper et al. [45] used the antibody at low concentration. Thus, their results would be in line with transcriptome data (see above). In the cerebellum, Rab6B was reported to be specifically expressed in microglia, pericytes, and Purkinje cells, however, by comparing the pattern of Rab6B staining with that of cell type-specific labelling in different sections [25]. The issue of astrocyte identity has been complicated by that of astrocyte heterogeneity, which is multi-dimensional with approaches addressing morphology, function, gene expression, physiology, development, disease, or aging (reviewed by $[28,35,46-52])$. Our data do not add to the multiple facets of astrocytes; on the contrary, they supply an additional, global descriptor of astrocyte identity, v.z. expression of Rab6A. Strictly speaking, the data are limited to the mouse and human brain, and do not permit extrapolation to other species, development, aging, or disease. Given the pan-astrocytic and specific distribution of Rab6A, as well as the high phylogenetic conservation of Rab6 [20], it might be speculated that the as yet unknown function of astrocytic Rab6A is crucial for the CNS, and that Rab6A, like GS, is expressed by astrocytes in vertebrate species in general $[29,53]$. However, this remains the object of future studies.

In the human, all GFAP ${ }^{+}$non-reactive astrocytes examined were Rab6 ${ }^{+}$. We regard the $\mathrm{GFAP}^{+} / \mathrm{Rab}^{-} \mathrm{A}^{-}$astrocytes found as associated with pathology (see below), since they constituted $12 \%$ of reactive astrocytes and were only observed in tissue from patient case I (FCD). We, therefore, suggest that Rab6A is a specific and selective glial marker also in the human, even though double staining for non-astrocytic glial cells was not performed.

\subsection{Astrocyte Cell Biology}

Our astrocyte classification into types I-IV, on the basis of Rab6A, did not result from unbiassed analysis (e.g., cluster analysis), but was post hoc following microscopic inspection. Intracellular Rab6A grains were found to be heterogeneous with respect to subcellular distribution, morphology, size, and number per cell. These parameters appear to be linked, which led to the classification (types I-IV, see Table 4). There were definitely many "transitional" cells that cannot be assigned to one of the types I-IV. We do not propose that astrocyte types I-IV represent discrete glial subtypes; we feel it more appropriate regarding types I-IV as intermediate states of dynamic processes within the cell. For further comment on the astrocyte types I-IV, it is interesting to consider the nature of the Rab6A+ structures. Rab6 is known as a marker of the TGN, and in other cell types, Rab6 localizes to late Golgi cisterns, the TGN, as well as TGN-derived cisterns and vesicles [20]. We believe that also in astrocytes, the fluorescent Rab6A grains of varying size and shape are membrane-bound organelles. The larger and medium sized Rab6 ${ }^{+}$ structures observed in perinuclear position and in stem processes may be larger cisterns or cisterns at intermediate stages of fragmentation, respectively, while the very small Rab6 ${ }^{+}$ puncta at the limit of microscopic resolution may be vesicles. As part of TGN development, large TGN cisterns originate near the Golgi, break up into smaller cisterns, and give rise to many small vesicles that bud off from the cisterns, thus consuming them [24]. Since Rab6 ${ }^{+}$ structures also "fill" the astrocytic stem and peripheral processes, it is conceivable that astrocytic TGN cisterns may be transported to sites very distant from the soma, where they fragment and bud off small vesicles. In this light, the astrocyte types I-IV, in reverse order, might correspond to TGN development. As a summary observation, the number of Rab6 $\mathrm{A}^{+}$ puncta successively increased from type VI-I, while their size decreased concomitantly, 
from the few large, perinuclear Rab6A "lumps" (type IV) to medium-sized and more frequent small grains (types III-I; Figure 6 and Figure S10). It remains completely unclear as to whether type IV astrocytes and its TGN develop to types III-I, or remain at that stage. In any case, the morphological data show that there is some degree of regulation of astrocytic TGN development, be it intrinsically or by intercellular signaling, for example, by neuronal activity.

It is interesting to note here that the few Rab6 $\mathrm{A}^{-}$astrocytes found were reactive and restricted to one of the two cases of FCD. It may be hypothesized that absence or suppression of TGN development in these astrocytes may result from extrinsic, pathology-associated biological mechanisms. Alternatively, Rab6 $\mathrm{A}^{-}$astrocytes may represent a particular type of astrocytic reactivity involving loss of general astrocyte features, such as GS expression, which is also downregulated, e.g., in epilepsy [54,55].

The study in human tissue, although limited, is conclusive about the general presence of Rab6A in astrocytes in the human, but the neuropathological findings from three cases are a non-representative, initial pilot study, suggesting that reactive astrocytes are mostly Rab6 $\mathrm{A}^{+}$, but can be Rab6A-. It prompts systematic pathological studies aimed at understanding both the possible role of astroglial Rab6A in pathology and its function in the brain.

Astrocytic Rab6A ${ }^{+}$TGN organelles are demonstrated here to be ubiquitous and abundant in the brain, and Rab6 is evolutionary highly conserved [20]. Cell biological studies will have to clarify whether these TGN vesicles recycle, for example, to the ER, or are targeted to the plasma membrane for endocytosis and/or exocytosis.

Ongoing studies aim at testing whether Rab6 $\mathrm{A}^{+}$TGN-derived vesicles are exocytosed in astrocytes. If so, this might shed a light on the identity of glial organelles related to release of transmitters and proteins involved in glia-neuronal communication [10,15-19], mechanisms known to regulate vital functions [56] and behavior [1-8].

We show here that Rab6A is a pan-astrocytic marker, a marker specific and common to all astrocytes. The data also confirm the global and specific astrocytic labelling by Aldh1L1 in gray matter, and the astrocyte-specific labelling by GS, which is sometimes debated [28,29], was replicated again. In both mouse and human brain, individual astrocytes display a variability in subcellular distribution, size, and number of Rab6 ${ }^{+}$structures, suggesting dynamic regulation of the glial TGN.

\section{Supplementary Materials:}

The following are available online at https: / www.mdpi.com/2073-4409/10/1/72/s1,

Figure S1: Procedure for assessing cellular colocalization without morphological bias.

Figure S2: Rab6A staining is ubiquitous in all brain regions, as exemplified in four other regions.

Figure S3: Different patterns in Rab6 ${ }^{+}$staining are typical of astrocytes.

Figure S4: Rab6A ${ }^{+}$structures in the fascia dentata.

Figure S5: Rab6A localizes to $\mathrm{GFAP}^{+}$astrocytes.

Figure S6: Rab6A ${ }^{+}$in perivascular glial endfeet.

Figure S7: Rab6A localizes specifically to astrocytes.

Figure S8: False positive Rab6A staining in microglia may be induced by the detection system.

Figure S9: Neurons are Rab6-.

Figure S10: Quantitation of Rab6A ${ }^{+}$structures.

Figure S11: Some of the human $\mathrm{GFAP}^{+}$astrocytes are Rab6A-.

Figure S12: Classification of Rab6 ${ }^{+}$astrocytes in human cortex.

Table S1: Number of astrocytes (A) and non-astrocytic cells (B) checked.

Diagram S1: Localization of Rab6A in $\mathrm{GFAP}^{+}$astrocytes.

Diagram S2: Localization of Rab6A in Sox9 ${ }^{+}$astrocytes.

Diagram S3: Localization of GS in GFAP $\mathrm{Gab}^{+} / \mathrm{Ra}^{+}$astrocytes.

Diagram S4: Localization of Aldh1L1 in $\mathrm{GFAP}^{+} / \mathrm{Rab}^{+}$astrocytes.

Diagram S5: Localization of Rab6A in $\mathrm{GS}^{+}$astrocytes.

Diagram S6: Localization of Rab6A in Aldh1L1+ astrocytes.

Diagram S7: Localization of GFAP in $\mathrm{GS}^{+} / \mathrm{Rab}^{+} \mathrm{A}^{+}$astrocytes.

Diagram S8: Localization of GFAP in Aldh1L1+ ${ }^{+}$Rab6A ${ }^{+}$astrocytes. 
Author Contributions: Conceptualization, A.D.; validation, A.D. and L.M.; formal analysis, L.M.; investigation, L.M.; resources, T.M.F.; data curation, L.M.; writing-original draft preparation, A.D.; writing-review and editing, A.D. and L.M.; visualization, L.M.; supervision, A.D. All authors have read and agreed to the published version of the manuscript.

Funding: This research received no external funding.

Institutional Review Board Statement: The study was conducted according to the guidelines of the Declaration of Helsinki, and approved by the local Ethics Committee (Medical Faculty, GoetheUniversität Frankfurt am Main, code nr. 4/09; Project-Nr. SNO-09-2014).

Informed Consent Statement: Informed consent was obtained from all subjects involved in the study.

Data Availability Statement: No new data outside those presented in this study were created or analyzed. Data sharing is not applicable to this article.

Acknowledgments: The technical assistance of Doris Evers and Elke Laedke is gratefully acknowledged.

Conflicts of Interest: The authors declare that they have no conflict of interest.

\section{References}

1. Martin, R.; Bajo-Grañeras, R.; Moratalla, R.; Perea, G.; Araque, A. Circuit-specific signaling in astrocyte-neuron networks in basal ganglia pathways. Science 2015, 349, 730-734. [CrossRef] [PubMed]

2. Oliveira, J.F.; Sardinha, V.M.; Guerra-Gomes, S.; Araque, A.; Sousa, N. Do stars govern our actions? Astrocyte involvement in rodent behavior. Trends Neurosci. 2015, 38, 535-549. [CrossRef] [PubMed]

3. Papouin, T.; Dunphy, J.M.; Tolman, M.; Dineley, K.T.; Haydon, P.G. Septal cholinergic neuromodulation tunes the astrocytedependent gating of hippocampal NMDA receptors to wakefulness. Neuron 2017, 94, 840-854.e7. [CrossRef] [PubMed]

4. Perea, G.; Sur, M.; Araque, A. Neuron-glia networks: Integral gear of brain function. Front. Cell. Neurosci. 2014, 8, 378. [CrossRef]

5. Perea, G.; Gómez, R.; Mederos, S.; Covelo, A.; Ballesteros, J.J.; Schlosser, L.; Hernández-Vivanco, A.; Martín-Fernández, M.; Quintana, R.; Rayan, A.; et al. Activity-dependent switch of GABAergic inhibition into glutamatergic excitation in astrocyteneuron networks. eLife 2016, 5, 1250. [CrossRef]

6. Sun, H.; Li, R.; Xu, S.; Liu, Z.; Ma, X. Hypothalamic Astrocytes Respond to Gastric Mucosal Damage Induced by Restraint Water-Immersion Stress in Rat. Front. Behav. Neurosci. 2016, 10, 210. [CrossRef]

7. Sweeney, P.; Qi, Y.; Xu, Z.; Yang, Y. Activation of hypothalamic astrocytes suppresses feeding without altering emotional states. Glia 2016, 64, 2263-2273. [CrossRef]

8. Yang, L.; Qi, Y.; Yang, Y. Astrocytes control food intake by inhibiting AGRP neuron activity via adenosine A1 receptors. Cell Rep. 2015, 11, 798-807. [CrossRef]

9. Araque, A.; Carmignoto, G.; Haydon, P.G.; Oliet, S.H.R.; Robitaille, R.; Volterra, A. Gliotransmitters travel in time and space Neuron 2014, 81, 728-739. [CrossRef]

10. Ryczko, D.; Hanini-Daoud, M.; Condamine, S.; Bréant, B.J.B.; Fougère, M.; Araya, R.; Kolta, A. Astrocytic modulation of information processing by layer 5 pyramidal neurons of the mouse visual cortex. bioRxiv 2020. [CrossRef]

11. Bergersen, L.; Morland, C.; Ormel, L.; Rinholm, J.E.; Larsson, M.; Wold, J.F.H.; Røe, Å.T.; Stranna, A.; Santello, M.; Bouvier, D.S.; et al. Immunogold detection of L-glutamate and D-serine in small synaptic-like microvesicles in adult hippocampal astrocytes. Cereb. Cortex 2012, 22, 1690-1697. [CrossRef] [PubMed]

12. Bezzi, P.; Gundersen, V.; Galbete, J.L.; Seifert, G.; Steinhäuser, C.; Pilati, E.; Volterra, A. Astrocytes contain a vesicular compartment that is competent for regulated exocytosis of glutamate. Nat. Neurosci. 2004, 7, 613-620. [CrossRef] [PubMed]

13. Jourdain, P.; Bergersen, L.H.; Bhaukaurally, K.; Bezzi, P.; Santello, M.; Domercq, M.; Matute, C.; Tonello, F.; Gundersen, V.; Volterra, A. Glutamate exocytosis from astrocytes controls synaptic strength. Nat. Neurosci. 2007, 10, 331-339. [CrossRef] [PubMed]

14. Martineau, M.; Shi, T.; Puyal, J.; Knolhoff, A.M.; Dulong, J.; Gasnier, B.; Klingauf, J.; Sweedler, J.V.; Jahn, R.; Mothet, J.-P. Storage and uptake of D-serine into astrocytic synaptic-like vesicles specify gliotransmission. J. Neurosci. 2013, 33, 3413-3423. [CrossRef] [PubMed]

15. Gundersen, V.; Storm-Mathisen, J.; Bergersen, L.H. Neuroglial Transmission. Physiol. Rev. 2015, 95, 695-726. [CrossRef]

16. Jorgačevski, J.; Potokar, M.; Kreft, M.; Guček, A.; Zorec, R.; Mothet, J.-P. Astrocytic vesicle-based exocytosis in cultures and acutely isolated hippocampal rodent slices. J. Neurosci. Res. 2017, 95, 2152-2158. [CrossRef]

17. Sahlender, D.A.; Savtchouk, I.; Volterra, A. What do we know about gliotransmitter release from astrocytes? Philos. Trans. R. Soc. Lond. B Biol. Sci. 2014, 369, 20130592. [CrossRef]

18. Schwarz, Y.; Zhao, N.; Kirchhoff, M.F.; Bruns, D. Astrocytes control synaptic strength by two distinct v-SNARE-dependent release pathways. Nat. Neurosci. 2017, 20, 1529-1539. [CrossRef]

19. Verkhratsky, A.; Matteoli, M.; Parpura, V.; Mothet, J.-P.; Zorec, R. Astrocytes as secretory cells of the central nervous system: Idiosyncrasies of vesicular secretion. EMBO J. 2016, 35, 239-257. [CrossRef]

20. Goud, B.; Akhmanova, A. Rab6 GTPase. In Rab GTPases and Membrane Trafficking; Li, G., Segev, N., Eds.; Bentham eBooks: Dubai, UAE, 2012; pp. 34-46.

21. Stenmark, H.; Olkkonen, V.M. The Rab GTPase family. Genome Biol. 2001, 2, 3007.1-3007.7. [CrossRef] 
22. Young, J.; Ménétrey, J.; Goud, B. RAB6C is a retrogene that encodes a centrosomal protein involved in cell cycle progression. J. Mol. Biol. 2010, 397, 69-88. [CrossRef] [PubMed]

23. Grigoriev, I.; Splinter, D.; Keijzer, N.; Wulf, P.S.; Demmers, J.; Ohtsuka, T.; Modesti, M.; Maly, I.V.; Grosveld, F.; Hoogenraad, C.C.; et al. Rab6 regulates transport and targeting of exocytotic carriers. Dev. Cell 2007, 13, 305-314. [CrossRef] [PubMed]

24. Miserey-Lenkei, S.; Chalancon, G.; Bardin, S.; Formstecher, E.; Goud, B.; Echard, A. Rab and actomyosin-dependent fission of transport vesicles at the Golgi complex. Nat. Cell Biol. 2010, 12, 645-654. [CrossRef] [PubMed]

25. Opdam, F.J.; Echard, A.; Croes, H.J.; van den Hurk, J.A.; van de Vorstenbosch, R.A.; Ginsel, L.A.; Goud, B.; Fransen, B. The small GTPase Rab6B, a novel Rab6 subfamily member, is cell-type specifically expressed and localised to the Golgi apparatus. J. Cell Sci. 2000, 113, 2725-2735. [PubMed]

26. Anlauf, E.; Derouiche, A. A practical calibration procedure for fluorescence colocalization at the single organelle level. J. Microsc. 2009, 233, 225-233. [CrossRef] [PubMed]

27. Verkhratsky, A.; Nedergaard, M. Physiology of Astroglia. Physiol. Rev. 2018, 98, 239-389. [CrossRef]

28. Rasband, W.S.; ImageJ. U. S. National Institutes of Health, Bethesda, Maryland, USA. 1997-2018. Available online: http:/ /imagej.nih.gov/ij/ (accessed on 6 August 2020).

29. Anlauf, E.; Derouiche, A. Glutamine synthetase as an astrocytic marker: Its cell type and vesicle localization. Front. Endocrinol. 2013, 4, 144. [CrossRef] [PubMed]

30. Cahoy, J.D.; Emery, B.; Kaushal, A.; Foo, L.C.; Zamanian, J.L.; Christopherson, K.S.; Xing, Y.; Lubischer, J.L.; Krieg, P.A.; Krupenko, S.A.; et al. A transcriptome database for astrocytes, neurons, and oligodendrocytes: A new resource for understanding brain development and function. J. Neurosci. 2008, 28, 264-278. [CrossRef]

31. Neymeyer, V.; Tephly, T.R.; Miller, M.W. Folate and 10-formyltetrahydrofolate dehydrogenase (FDH) expression in the central nervous system of the mature rat. Brain Res. 1997, 766, 195-204. [CrossRef]

32. Sun, W.; Cornwell, A.; Li, J.; Peng, S.; Osorio, M.J.; Aalling, N.; Wang, S.; Benraiss, A.; Lou, N.; Goldman, S.A.; et al. SOX9 Is an astrocyte-specific nuclear marker in the adult brain outside the neurogenic regions. J. Neurosci. 2017, 37, 4493-4507. [CrossRef]

33. Theofilas, P.; Steinhäuser, C.; Theis, M.; Derouiche, A. Morphological study of a connexin 43-GFP reporter mouse highlights glial heterogeneity, amacrine cells, and olfactory ensheathing cells. J. Neurosci. Res. 2017, 95, 2182-2194. [CrossRef] [PubMed]

34. Escartin, C.; Guillemaud, O.; Carrillo-de Sauvage, M.-A. Questions and (some) answers on reactive astrocytes. Glia 2019, 67, 2221-2247. [CrossRef] [PubMed]

35. Yang, Y.; Vidensky, S.; Jin, L.; Jie, C.; Lorenzini, I.; Frankl, M.; Rothstein, J.D. Molecular comparison of GLT1 ${ }^{+}$and ALDH1L1 ${ }^{+}$ astrocytes in vivo in astroglial reporter mice. Glia 2011, 59, 200-207. [CrossRef] [PubMed]

36. Kimelberg, H.K. The problem of astrocyte identity. Neurochem. Int. 2004, 45, 191-202. [CrossRef]

37. Doyle, J.P.; Dougherty, J.D.; Heiman, M.; Schmidt, E.F.; Stevens, T.R.; Ma, G.; Bupp, S.; Shrestha, P.; Shah, R.D.; Doughty, M.L.; et al. Application of a translational profiling approach for the comparative analysis of CNS cell types. Cell 2008, 135, 749-762. [CrossRef]

38. Lovatt, D.; Sonnewald, U.; Waagepetersen, H.S.; Schousboe, A.; He, W.; Lin, J.H.-C.; Han, X.; Takano, T.; Wang, S.; Sim, F.J.; et al. The Transcriptome and Metabolic Gene Signature of Protoplasmic Astrocytes in the Adult Murine Cortex. J. Neurosci. 2007, 27, 12255-12266. [CrossRef]

39. Zhang, Y.; Chen, K.; Sloan, S.A.; Bennett, M.L.; Scholze, A.R.; O'Keeffe, S.; Phatnani, H.P.; Guarnieri, P.; Caneda, C.; Ruderisch, N.; et al. An RNA-sequencing transcriptome and splicing database of glia, neurons, and vascular cells of the cerebral cortex. J. Neurosci. 2014, 34, 11929-11947. [CrossRef]

40. Nizak, C.; Monier, S.; Del Nery, E.; Moutel, S.; Goud, B.; Perez, F. Recombinant antibodies to the small GTPase Rab6 as conformation sensors. Science 2003, 300, 984-987. [CrossRef]

41. Müller, J.; Rana, N.A.; Serth, K.; Kakuda, S.; Haltiwanger, R.S.; Gossler, A. O-fucosylation of the notch ligand mDLL1 by POFUT1 is dispensable for ligand function. PLOS ONE 2014, 9, e88571. [CrossRef]

42. Cayre, S.; Faraldo, M.M.; Bardin, S.; Miserey-Lenkei, S.; Deugnier, M.-A.; Goud, B. RAB6 GTPase regulates mammary secretory function by controlling the activation of STAT5. Development 2020, 147, dev190744. [CrossRef]

43. Feldmann, G.; Durand-Schneider, A.; Goud, B. Behavior of the small GTP-binding protein rab6 in the liver of normal rats and rats presenting an acute inflammatory reaction. Biol. Cell 1995, 83, 121-125. [CrossRef]

44. Huang, W.; Wu, G.; Wang, G.-Y. Cell type-specific and light-dependent expression of Rab1 and Rab6 GTPases in mammalian retinas. Vis. Neurosci. 2009, 26, 443-452. [CrossRef] [PubMed]

45. Scheper, W.; Hoozemans, J.J.M.; Hoogenraad, C.C.; Rozemuller, A.J.M.; Eikelenboom, P.; Baas, F. Rab6 is increased in Alzheimer's disease brain and correlates with endoplasmic reticulum stress. Neuropathol. Appl. Neurobiol. 2007, 33, 523-532. [CrossRef] [PubMed]

46. Bachoo, R.M.; Kim, R.S.; Ligon, K.L.; Maher, E.A.; Brennan, C.; Billings, N.; Chan, S.; Li, C.; Rowitch, D.H.; Wong, W.H.; et al. Molecular diversity of astrocytes with implications for neurological disorders. Proc. Natl. Acad. Sci. USA 2004, 101, 8384-8389. [CrossRef]

47. Chaboub, L.S.; Deneen, B. Developmental origins of astrocyte heterogeneity: The final frontier of CNS development. Dev. Neurosci. 2012, 34, 379-388. [CrossRef] 
48. Chai, H.; Diaz-Castro, B.; Shigetomi, E.; Monte, E.; Octeau, J.C.; Yu, X.; Cohn, W.; Rajendran, P.S.; Vondriska, T.M.; Whitelegge, J.P.; et al. Neural circuit-specialized astrocytes: Transcriptomic, proteomic, morphological, and functional evidence. Neuron 2017, 95, 531-549.e9. [CrossRef]

49. Khakh, B.S.; Deneen, B. The Emerging Nature of Astrocyte Diversity. Annu. Rev. Neurosci. 2019, 42, 187-207. [CrossRef]

50. Khakh, B.S.; Sofroniew, M.V. Diversity of astrocyte functions and phenotypes in neural circuits. Nat. Neurosci. 2015, 18, 942-952. [CrossRef]

51. Oberheim, N.A.; Goldman, S.A.; Nedergaard, M. Heterogeneity of astrocytic form and function. Methods Mol. Biol. 2011, 814, 23-45. [CrossRef]

52. Okuda, H. A review of functional heterogeneity among astrocytes and the CS56-specific antibody-mediated detection of a subpopulation of astrocytes in adult brains. Anat. Sci. Int. 2018, 93, 161-168. [CrossRef]

53. Wicht, H.; Derouiche, A.; Korf, H.-W. An immunocytochemical investigation of glial morphology in the Pacific hagfish: Radial and astrocyte-like glia have the same phylogenetic age. J. Neurocytol. 1994, 23, 565-576. [CrossRef] [PubMed]

54. Eid, T.; Thomas, M.J.; Spencer, D.D.; Rundén-Pran, E.; Lai, J.C.K.; Malthankar, G.V.; Kim, J.H.; Danbolt, N.C.; Ottersen, O.P.; de Lanerolle, N.C. Loss of glutamine synthetase in the human epileptogenic hippocampus: Possible mechanism for raised extracellular glutamate in mesial temporal lobe epilepsy. Lancet 2004, 363, 28-37. [CrossRef]

55. Eid, T.; Tu, N.; Lee, T.-S.W.; Lai, J.C. Regulation of astrocyte glutamine synthetase in epilepsy. Neurochem. Int. $2013,63,670-681$. [CrossRef] [PubMed]

56. Morquette, P.; Verdier, D.; Kadala, A.; Féthière, J.; Philippe, A.G.; Robitaille, R.; Kolta, A. An astrocyte-dependent mechanism for neuronal rhythmogenesis. Nat. Neurosci. 2015, 18, 844-854. [CrossRef] [PubMed] 